\title{
УДК 549.02:54.052:553.611.6 \\ МОНТМОРИЛЛОНИТ КАК ПЕРСПЕКТИВНЫЙ КОМПОЗИТНЫЙ МИНЕРАЛ ДЛЯ СОЗДАНИЯ СОВРЕМЕННЫХ УДОБРЕНИЙ ПРОЛОНГИРОВАННОГО ДЕЙСТВИЯ
}

\author{
Рудмин Максим Андреевич1, \\ rudminma@tpu.ru
}

Рева Игорь Витальевич1, igor_1993@mail.ru

\author{
Якич Тамара Юрьевна ${ }^{1}$, \\ cherkasovatu@tpu.ru
}

\author{
Буяков Алесь Сергеевич1,2 \\ alesbuyakov@gmail.com
}

Табакаев Роман Борисович 1 , TabakaevRB@tpu.ru

ибраева Канипа ${ }^{1}$, kti1@tpu.ru

\author{
Соктоев Булат Ринчинович1, \\ bulatsoktoev@tpu.ru \\ 1 Национальный исследовательский Томский политехнический университет, \\ Россия, 634050, г. Томск, пр. Ленина, 30. \\ 2 Институт физики прочности и материаловедения Сибирского отделения Российской академии наук, \\ Россия, 634055, г. Томск, пр. Академический, 2/4.
}

\begin{abstract}
Актуальность исследования. Решение экологических проблем в аграрном секторе возможно за счёт использования новых удобрений пролонгированного и контролируемого действия. В данной статье приводятся варианты использования монтмориллонита в качестве составного компонента современных азотных удобрений с контролируемыми свойствами и результаты изучения минеральных трансформаций в процессе механохимической активации при различных параметрах.

Основная цель работы заключалась в оценке механизмов активации монтмориллонита как ингибитора азотсодержащих композитных продуктов для создания удобрений пролонгированного действия.

Методы: механохимическая активация в планетарной и кольцевой мельницах, рентгенодифракционный анализ, сканирующая электронная микроскопия, инфрракрасная спектроскопия, диффференциальный термический анализ.

Выводы. Доля интеркалированной мочевины в монтмориллоните (для смесей M1N1) изменяется в пределах 22,3...23,2 \% при активации в планетарной мельнице в течении 3, 8 или 11 минут. Максимальная степень интеркаляции 23,2 \% была достигнута при активации в течении 3 минут. После 11-минутной операции около 40 ...50 \% агрегированных глинистых частии покрываются внешней оболочкой избыточной мочевины толщиной до 2,5 мкм. Доля интеркалированной мочевины в монтмориллоните изменяется с 23,2 до 21,6 \% по мере увеличения времени активации с 30 до 120 минут в кольцевой мельнице. По мере увеличения времени активации образуются микрокристаллиты мочевины на поверхности минеральных частиц. Минеральные продукты, полученные методом активации в планетарной или кольцевой мельницах, могут использоваться как удобрения пролонгированного действия с несколькими полезными функциями. Композиты, синтезированные при 11-минутной или 120-минутной работе планетарной или кольцевой мельниц, соответственно, характеризуются двумя типами азота. Изначально удобрения будут высвобождать нутриенты с высокой скоростью из внешней пленки, состоящей из мочевины, после чего будет расходоваться обменный азот из межслоевого пространства монтмориллонита, тем самым обеспечивая пролонгированное питание растений.
\end{abstract}

\section{Ключевые слова:}

Монтмориллонит, глинистые минералы, минеральные удобрения, механохимическая активация, азотные удобрения.

\section{Введение}

Благодаря повышению уровня использования удобрений и пестицидов, а также развитию новых культур и технологий за последние 50 лет объемы мирового сельскохозяйственного производства увеличились более чем в два раза [1]. Глобальное применение азотных удобрений выросло с 32 млн т в 1970 г. до примерно 111,6 млн т в 2016 г. (данные International Fertilizer Association (IFA) на ноябрь 2016 г.), и ожидается, что к 2050 г. оно составит около $130 \ldots 150$ млн т в год [2]. Внесение различных форм азота с уменьшением эффективности его усвоения способствует загрязнению окружающей среды, что отражается в ухудшении качества воды, эвтрофикации прибрежных морских экосистем, развитии фотохимического смога и повышении концентрации закиси азота в атмосфере как парникового газа [3, 4]. Китайское агрохозяйство как потребитель около 30 \% азотных удоб- рений от их общемировой доли одно из первых испытало экологический урон от бесконтрольного использования удобрений [5-9], что следует учитывать всем странам, с развивающимся сельскохозяйственным сектором и главным образом России.

Традиционные удобрения (например, мочевина) имеют низкую термостойкость, высокую растворимость и малый молекулярный вес. При внесении в почву нутриенты таких удобрений имеют тенденцию мигрировать в воздух и воду в результате улетучивания, стока и выщелачивания. $\mathrm{N}_{2} \mathrm{O}$, образующийся в процессе нитрификации-денитрификации, является важным парниковым газом, и его влияние на потепление климата в 298 раз выше, чем у $\mathrm{CO}_{2}$. Кроме того, $\mathrm{N}_{2} \mathrm{O}$ способен нанести ущерб озоновому слою. В системах сельскохозяйственного культивирования постоянное увеличение количества применяемых химических удобрений приводит к тому, что выбросы $\mathrm{N}_{2} \mathrm{O}$ 
и $\mathrm{CO}_{2}$ становятся крупнейшими источниками парниковых газов $[9,10]$. Чрезмерное внесение традиционных азотных удобрений приводит к низкому коэффициенту их использования (на уровне $30 \ldots 40 \%$ [9]), что не только приводит к завышенному использованию экономических ресурсов и увеличивает производственные затраты, но также снижает качество воздуха, почвы и воды [11].

Ключевая проблема низкого показателя эффективности связана с дисбалансом между питательными веществами, высвобождаемыми из традиционных удобрений, и поглощением этих нутриентов корнями растений, что приводит к потере и выбросу химических веществ (в том числе $\mathrm{N}_{2} \mathrm{O}$ ). Решение этой проблемы возможно за счёт использования комплексных удобрений «нового поколения», к которым относятся удобрения пролонгированного и контролируемого действия, так называемые «slow-release fertilizers - SRF» или «controlled-release fertilizers - $\mathrm{CRF}$ », соответственно $[1,2,9,12-20]$. Основная функция удобрений «адресного» действия заключается в постепенной отдаче нутриентов растениям с необходимой скоростью для уменьшения избытка этих компонентов в почвах [2123]. Создание таких удобрений основано на подборе веществ выполняющих роль «контейнера» и «заполнителя», и механизмов их синтеза/активирования.

Сегодня в качестве основных составных компонентов таких удобрений изучаются полимеры $[16,24,25]$, композиты из синтетических и природных веществ [26-29] и глинистые минералы (филлосиликаты): монтмориллонит [30-33], а также каолинит [34-36], пылагорскит [23, 28], хризотил [17], глауконит [37, 38]. При этом глинистые минералы имеют отдельный практический интерес, поскольку являются более дешевым материалом относительно синтетических продуктов.

В настоящей работе приводится исследование механизмов активации ценных свойств монтмориллонита для создания удобрений пролонгированного действия. Цель исследования - оценка перспектив монтмориллонита как ингибитора азотных соединений при двух вариантах механохимической активации из сухих смесей на основе анализа последуюших минеральных трансформащий. В качестве объекта выбран монтмориллонит как глинистый минерал, имеющий широкое распространение в пределах осадочных месторождений сибирских регионов, что позволяет рассматривать его как экономически доступное сырье для местного использования.

\section{1. Материал и методика исследования}

Для проведения механохимических испытаний использовались образцы монтмориллонитовой глины из славгородской свиты Бакчарского месторождения железа (Томская область). Глинистые породы славгородской свиты залегают как промежуточные слои между горизонтами железной руды в пределах месторождения на глубинах 205...240 м [39]. При будущей открытой эксплуатации месторождения эти толщи будут вскрышными породами и будут складироваться в горных отвалах. При этом вышезалегающие осадочные породы также представляют перспективы для использования в сель- ском хозяйстве [40-43]. Содержание монтмориллонита (или монтмориллонит-бейделлита с формулой $\left.\mathrm{Na}_{0.03} \mathrm{Ca}_{0.08}\left(\mathrm{Al}_{1.45} \mathrm{Mg}_{0.26} \mathrm{Fe}_{0.09}\right)_{1.8} \mathrm{Si}_{3.78} \mathrm{Al}_{0.22} \mathrm{O}_{10}(\mathrm{OH})_{2} \mathrm{nH}_{2} \mathrm{O}\right)$ в исследуемой пробе составляло 89,5\%.

Минералогические и структурные характеристики глинистого минерала определялись с использованием рентгенодифракционного анализа (РДА). Морфология глинистых частиц и характеристика их микроструктуры были изучены при помощи сканирующей электронной микроскопии (СЭМ). Структурные особенности оценивались с использованием дифференциального термического анализа (ДТА) и ИКспектрометрии (ИК).

Рентгенодифракционный анализ (РДА) производился на рентгеновском дифрактометре Bruker D2 Phaser c CuK излучением. Истертые до размера менее 10 мкм препараты сканировались в интервале углов $2 \theta 3 \ldots 70^{\circ}$ с шагом $0,02^{\circ}$, скоростью сканирования 2 с/точка, при параметрах измерения 40 кВ и 40 мА. СЭМ проводилась с использованием микроскопа TESCAN VEGA 3 SBU, оснащенного приставкой для рентгенофлуоресцентного энергодисперсионного анализа (ЭДС) OXFORD X-Max 50 c Si/Li кристаллическим детектором. Ускоряющее напряжение для СЭМ съемки и анализа было 20 кВ с интенсивностью тока зонда в пределах 4...12,2 нА. Термогравиметрический (ТГА) и дифференциальный термический (ДТА) анализы проводились с помощью термоанализатора STA 449 F5 Jupiter для модельного расчёта доли интеркалированного азота и изучения термической деструкции минерала. Анализ выполнялся при следующих параметрах: интервал температур $25 \ldots 1000{ }^{\circ} \mathrm{C}$, скорость нагрева $10 \mathrm{~K} /$ мин. Количество интеркалированной мочевины в монтмориллоните рассчитывалось как потеря массы в диапазоне 300 (290)...580 ${ }^{\circ} \mathrm{C}$. ИК-спектроскопия выполнялась с помощью ИК-Фурье спектрометра Shimadzu IR Prestige-21 в режиме поглощения, интервале частот $400 . .4000 \mathrm{~cm}^{-1}$ с разрешением $4 \mathrm{~cm}^{-1}$.

Опыты по механохимической активации смесей на основе монтмориллонита и мочевины в соотношении (минерал-мочевина) 1:1 (или 50:50 \%) выполнялись двумя способами в планетарной или кольцевой мельницах. В итоге последующие опыты проводились по следующей схеме. Изначально были подготовлены сухие смеси из монтмориллонита и мочевины в соотношении 1:1 (10 г монтмориллонита (монтмориллонитового концентрата) и 10 г мочевины). В итоге шесть смесей на основе монтмориллонита были активированы в различных вариантах времени (три для каждого способа) в двух мельницах. В результате два варианта активации было изучено. Один из них выполнялся в кольцевой мельнице (ROCKLABS Standard Ring Mill) с частотой вращения 700 об/мин и массовым соотношением порошков и мелющих тел 1:5. Три смеси монтмориллонита и мочевины (каждая весом 20 г), полученные после 30, 60 или 120 минут активации в кольцевой мельнице, обозначались как M1N1-rm30, M1N1rm60, M1N1-rm120, соответственно. Активация тех же исходных смесей проводилась отдельно в планетарной мельнице в течении 3,8 или 11 минут операционной 
работы с получением композитов M1N1-pm3, M1N1pm8, M1N1-pm11, соответственно. Активацию порошковых смесей проводили в планетарной мельнице АГО-2 с частотой вращения 1820 об/мин и соотношением порошков к мелющим телам 1:5.

\section{2. Результаты}

Минералогическая и морфологическая характеристика композитов на основе монтмориллонита и мочевины

По данным РДА (рис. 1) монтмориллонит (монтмориллонит-бейделлит) в активированных композитах (M1N1) показывает характерные дифракционные отражения при 16,9-17,4; 4,5; 4,3 и 3,4 А. Мочевина - при 4,7; 4,$0 ; 3,6 ; 3,1 ; 2,8 ; 2,5 ; 2,4 ; 2,2 ; 1,8$ и $1,7 \AA$. Интенсивность отражения при 4,0 $\AA$ связана с абсорбированной мочевиной и изменяется с увеличением времени активации. Первый базальный рефлекс сдвигается с 16,9 до 17,4 при увеличении времени активации с 30 до 120 мин в кольцевой мельнице (рис. 1). Аналогичный сдвиг наблюдается с 17,0 до 17,3 А̊ по мере увеличения времени работы планетарной мельницы с 3 до 11 мин.

По данным СЭМ для композитов характерно изменение морфоструктуры при разной продолжительности работы мельниц (рис. 2). Композит S1N1-pm11 характеризуется сплошным покрытием из мочевины, фор- мирующим «микрокапсулы» по активированным микрочешуйкам монтмориллонита. На СЭМ-снимках монтмориллонит представлен чешуйчатыми ультрамикроагрегатами, в то время как мочевина - микрокристаллитами или тонкой пленкой. Пленка мочевины в композите S1N1-pm3 имеет неправильные и «рваные» очертания с неровной поверхностью (рис. 2, a). Толщина пленки изменяется от 50 до 200 нм. Композит S1N1-pm8 имеет тонкое покрытие толщиной 400...800 нм из мочевины на поверхности частиц монтмориллонита (рис. 2, б). Покрытие того же состава в композите S1N1-pm11 утолщается до 1...2,5 мкм и становится сплошным. Композит S1N1-pm11 состоит из сферических микроагрегатов размером от 1 до 10 мкм с прослоями монтмориллонита с абсорбированным азотом в «ядерной» части и внешним азотным покрытием (рис. 2, в). Такие формы условно обозначаются как микрокапсулы с двумя формами азота: (1) интеркалированным в монтмориллонит и (2) адсорбированным на поверхности активированных глинистых ультрамикроагрегатов. Доля адсорбированной мочевины во всех композитах, синтезированных в планетарной мельнице, составляет 7..11 вес. \% по данным ЭДС анализа поверхности частиц.
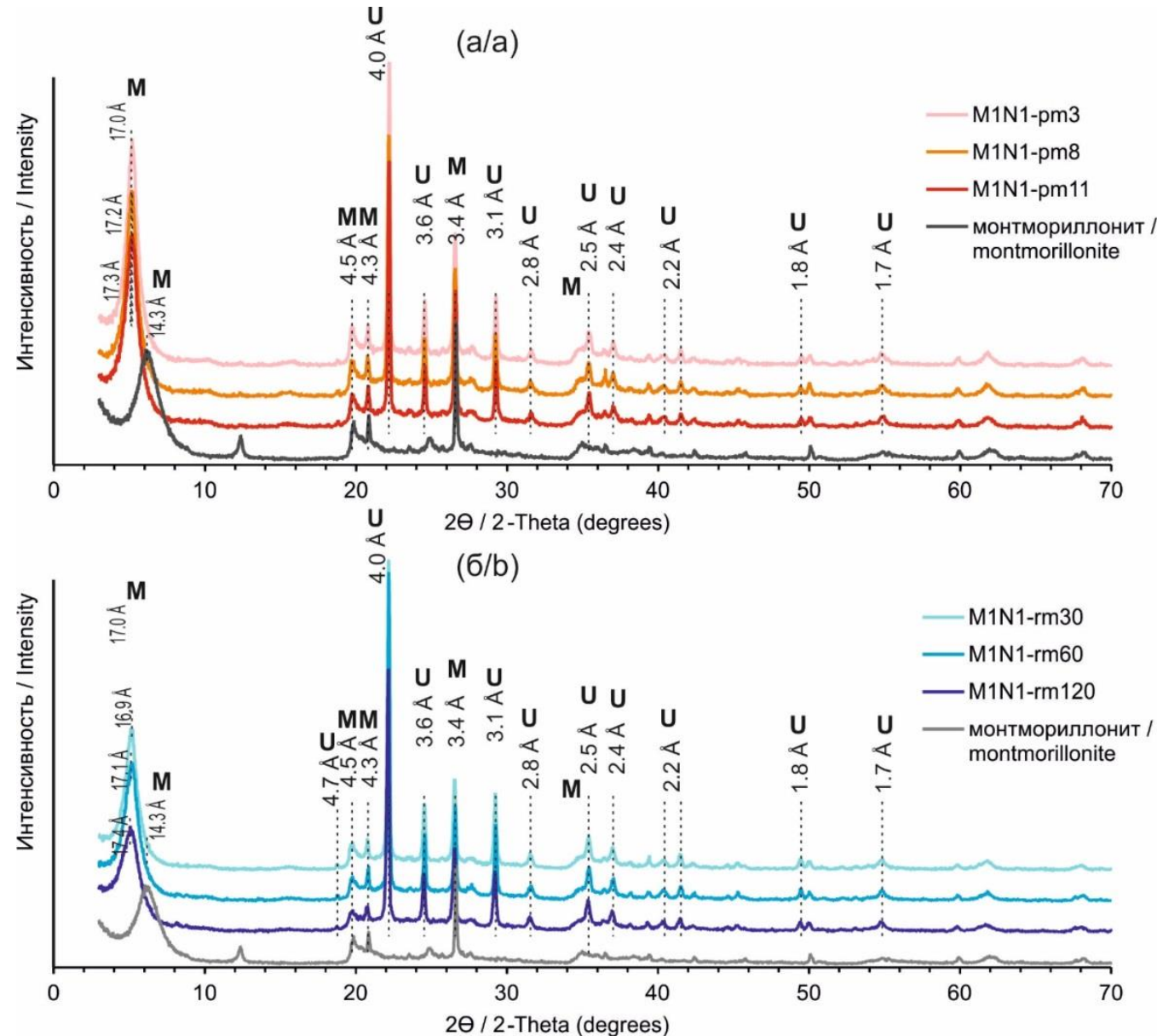

Рис. 1. Рентгеновские дифрактограммы композитов на основе смесей монтмориллонита (M) и мочевины (U) с соотношением 1:1, приготовленных в планетарной (а) или кольцевой (б) мельницах при разном времени активации

Fig. 1. XRD patterns of composites based on montmorillonite $(M)$ and urea $(U)$ mixtures in ratio 1:1 prepared using planetary $(a)$ or ring $(b)$ mills for different grinding times 
Монтмориллонит имеет чешуйчатую структуру в композите S1N1-rm30, а мочевина образует локальные пленки на активированном минерале (рис. 2, г). В композите S1N1-rm60 (рис. 2, д) монтмориллонит имеет пластинчатый вид. Микрокристаллиты мочевины образуют прерывистые скопления (локальные пленки) на некоторых микроагрегатах (рис. 2, г). В композите S1N1-rm120 (рис. 2, е) монтмориллонит и мочевина показывают максимальное внедрение микрокристаллитов. В композите S1N1-rm120 образуются микроагрегаты с минералом и асборбированным азотом в «ядре» и внешним прерывистым покрытием из микрокристаллитов мочевины (карбамида).
Пленка мочевины постепенно утолщается с увеличением продолжительности работы мельниц при каждом способе получения композитов. Однако равномерное покрытие (микрокапсула) из мочевины образуется в единственном опыте 11-минутной активации в планетарной мельнице. При этом синтезе в планетарной мельнице внешнее азотное покрытие более выдержанное, имеет повышенную толщину (до 2,5 мкм) и капсулирует (покрывает) около 40...50 \% минеральных частиц композита. Однако даже при 120-минутной активации в кольцевой мельнице это покрытие имеет «рваный» (прерывистый) характер, меньшую толщину (не более 500 нм) относительно S1N1pm8/11 и развивается по 20...30 \% минеральных частиц композита.
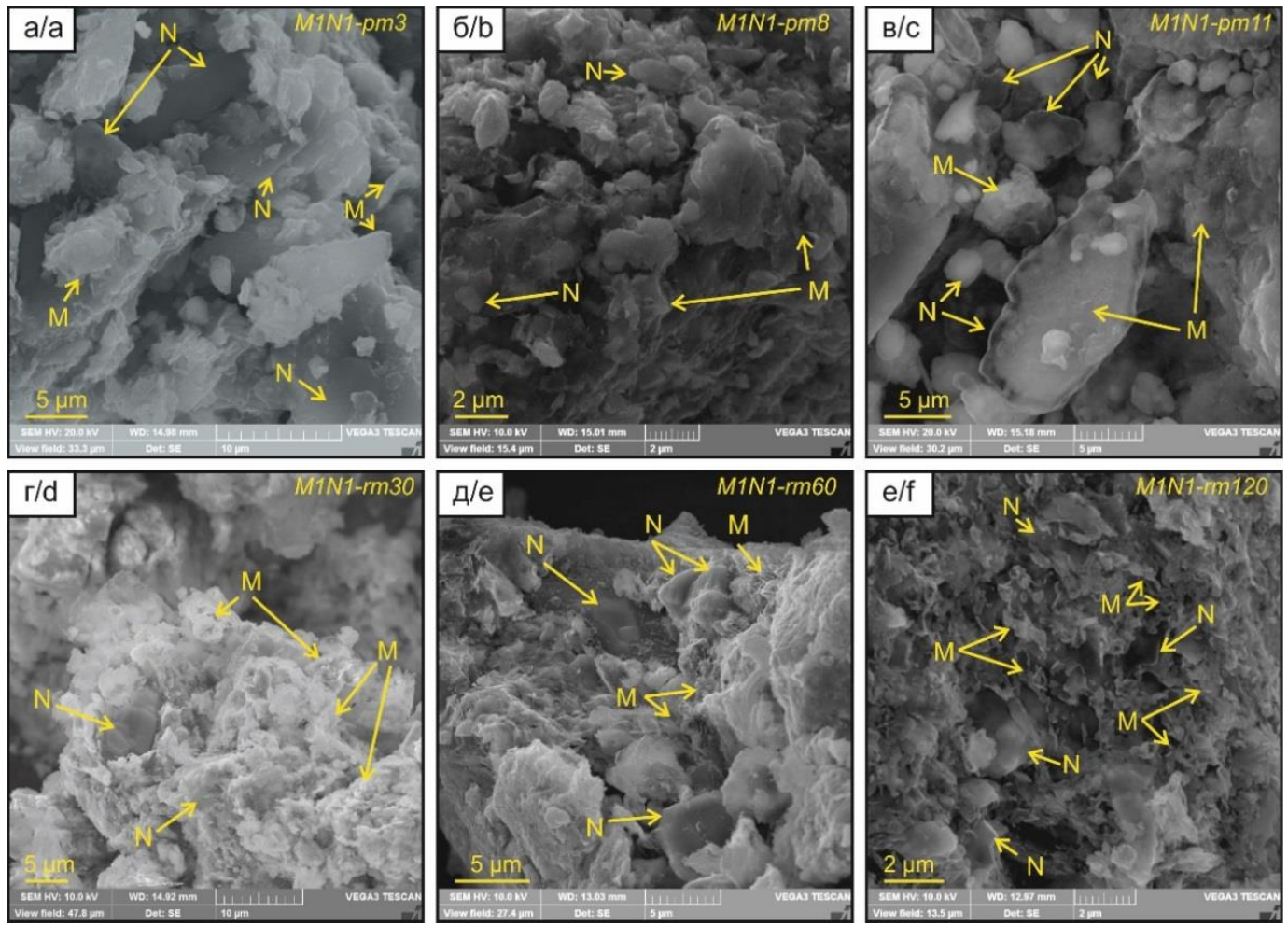

Pис. 2. Репрезентативные СЭМ-изображения композитов, приготовленных путем активации монтмориллонит (M) и мочевины (N) в соотношении 1:1 в планетарной (a-8) и кольцевой (2-e) мельницах

Fig. 2. Representative SEM images of composites prepared by activation of montmorillonite $(M)$ and urea $(N)$ in planetary $(a-c)$ and ring $(d-f)$ mills

Структурная характеристика композитов на основе монтмориллонита и мочевины

Композиты M1N1-pm3/8/11 и S1N1-rm30/60/120 демонстрируют пики ИК-поглощения $\mathrm{NH}_{2}$ и $\mathrm{CO}$ при 720 и $790 \mathrm{~cm}^{-1}$, соответственно (рис. 3). Композиты M1N1-pm3/8 и M1N1-rm30/60/120 показывают колебания растяжения Si-O при $1050 \mathrm{~cm}^{-1}$, что отражает структуру монтмориллонита. Пик $\mathrm{NH}_{2}$ при $1155 \mathrm{~cm}^{-1}$ наиболее интенсивен для композитов M1N1-pm11 и M1N1-rm120. Асимметричные деформации CN при $1463 \mathrm{~cm}^{-1}$ характерны для всех композитов, синтезированных из смесей монтмориллонита и карбамида в планетарной или кольцевой мельницах. Те же композиты показывают пик $\mathrm{NH}_{2}$ при $1595 \ldots 1608 \mathrm{~cm}^{-1}$ и пик $\mathrm{NH}$ при $1681 \ldots 1708 \mathrm{~cm}^{-1}$. Эти два пика имеют слабые флуктуации и смещаются в направлении повышен- ных частот для M1N1-pm3/8 за счет интеркаляции азота. Пик $\mathrm{NH}_{2}$ смещается от $3468 \mathrm{~cm}^{-1}$ (M1N1-pm3) до $3500 \mathrm{~cm}^{-1}$ (M1N1-pm8). Пик NH смещается в сторону меньших частот от 3344 до $3329 \mathrm{~cm}^{-1}$ для M1N1pm11. Все композиты на основе монтмориллонита показывают пик $3620 \mathrm{~cm}^{-1}$, который связан с колебаниями Al-OH-Al минерала (рис. 3).

Термогравиметрические (ТГ) кривые активированных композитов отражают пять этапов потери веca (рис. 4): $0 \ldots 135{ }^{\circ} \mathrm{C}, 135 \ldots 240{ }^{\circ} \mathrm{C}, 240 \ldots 365{ }^{\circ} \mathrm{C}$, $365 \ldots 580{ }^{\circ} \mathrm{C}, 580 \ldots 1000{ }^{\circ} \mathrm{C}$. Композиты показывают потерю массы на $0,7 \ldots 1,2$ и 24,9...25,8 \% в диапазонах $20 \ldots 135{ }^{\circ} \mathrm{C}$ и $135 \ldots 240{ }^{\circ} \mathrm{C}$, соответственно (рис. 4). Это относится к удалению свободной воды и разложению адсорбированной (неинтеркалированной) мочевины [18, 44]. Третий этап потери массы 
$240 \ldots 365{ }^{\circ} \mathrm{C}$ характеризует удаление абсорбированной и интеркалированной мочевины $[45,46]$ из композитов M1N1. В этом случае абсорбированная мочевина удаляется на 3,5..5,2 \% на субэтапе от 240 до $290 \ldots 300{ }^{\circ} \mathrm{C}$, интеркалированный азот - 13,3...18,6 \% на субэтапе $300 \ldots 365^{\circ} \mathrm{C}$. Четвертый этап потери веса в интервале температур $365 \ldots 580{ }^{\circ} \mathrm{C}$ относится к высвобождению инкапсулированной мочевины [8] и ха-

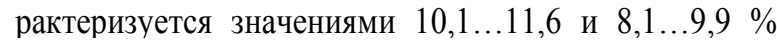
для композитов M1N1-pm и M1N1-rm, соответственно. В результате доля интеркалированной мочевины составляет 22,3...23,2 \% для M1N1-pm (рис. 4, a) и
21,6...23,2 \% для M1N1-rm (рис. 4, б). Пятая стадия потери массы в интервале температур $580 \ldots 1000{ }^{\circ} \mathrm{C}$ относится к дегидроксилации монтмориллонита [47], что характерно на 2,1 ..2,7 и 0,7 ..1,3 \% для композитов, синтезированных в планетарной или кольцевой мельницах, соответственно. Конечный остаток вещества после $540 \ldots 620^{\circ} \mathrm{C}(45,8 \ldots 47,6 \%)$ соответствует исходному пропорциональному содержанию минералов (около 50 \%). Максимальная интеркаляция мочевины в монтмориллонит происходила при времени активации 3 и 60 мин для планетарной и кольцевой мельниц, соответственно.
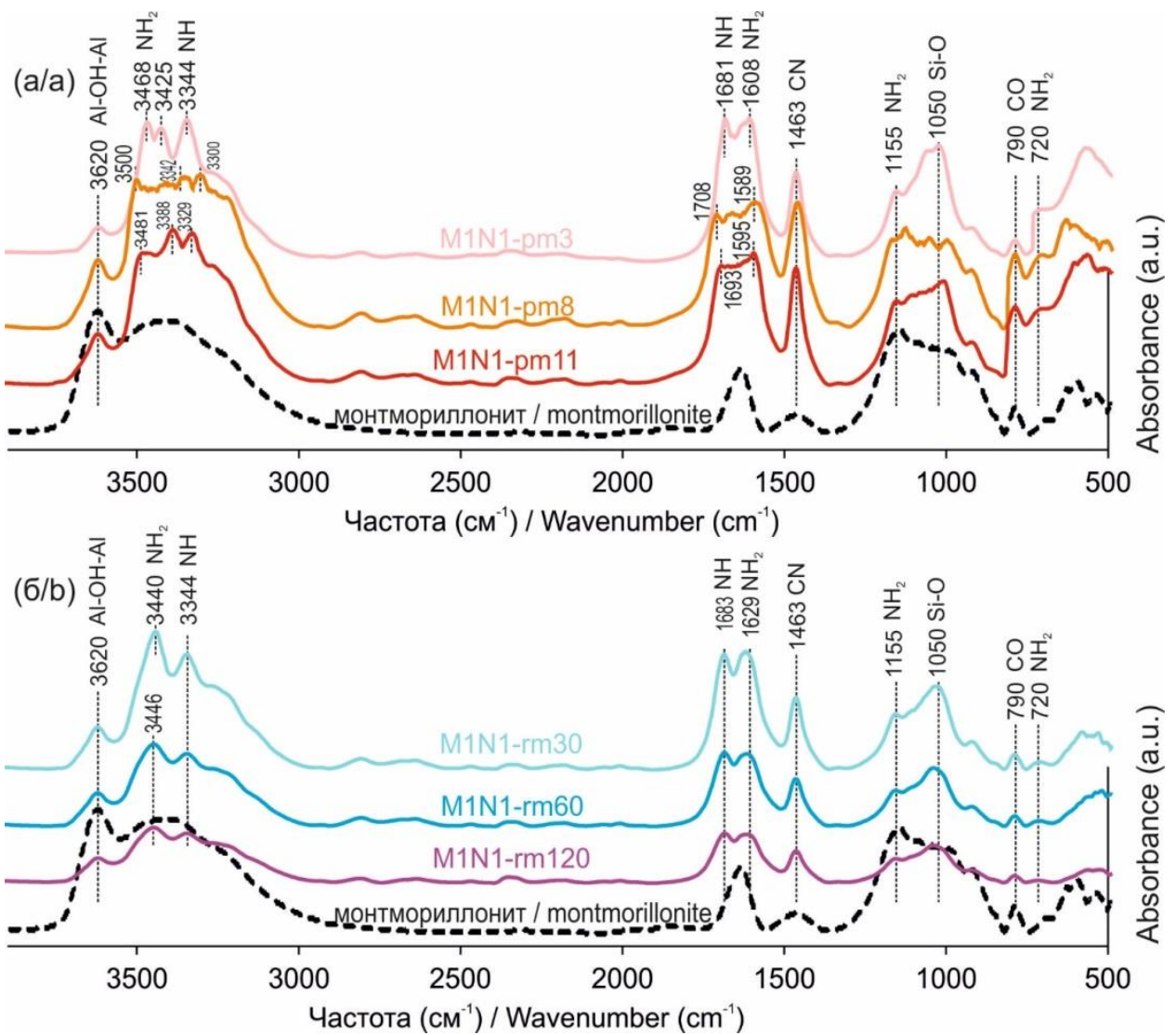

Рис. 3. ИК-Фурье спектры композитов монтмориллонит-мочевина (MIN1) с интерпретацией, синтезированных в планетарной (а) и кольцевой мельницах (б)

Fig. 3. FTIR spectra of montmorillonite-urea composite with interpretation prepared in (a) planetary and (b) ring mills
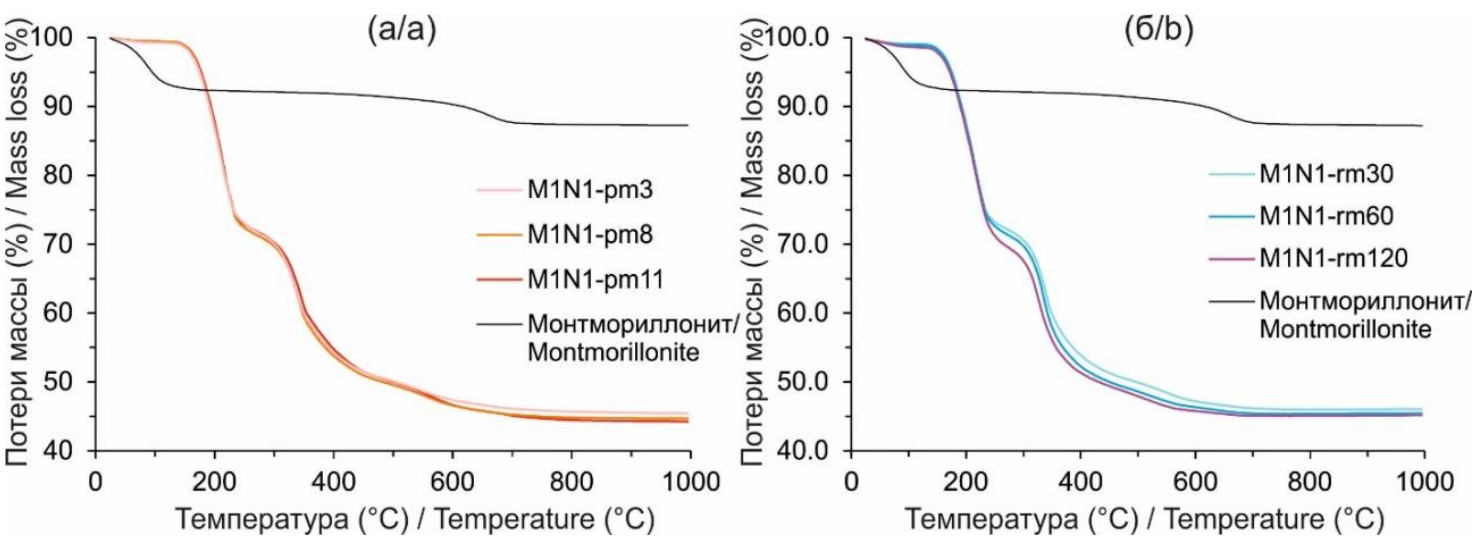

Рис. 4. ТГ-кривые композитов на основе монтмориллонита и мочевины, приготовленные при планетарном (a) и кольиевом (б) измельчении с различным операционным временем

Fig. 4. TG patterns of montmorillonite-urea mixtures prepared in (a) planetary and (b) ring milling at different times 


\section{3. Обсуждение результатов}

Степень внедрения мочевины в монтмориллонит в смесях с изначальным соотношением 50:50 изменяется в зависимости от активации в планетарной или кольцевой мельницах. Относительно ранних авторских опытов с синтезом композитов на основе смесей смектит-мочевина в соотношении 40:60 [37], описанная выше активация отличается меньшим временем работы планетарной мельницы, составом и изначальной долей минерала.

По мере увеличения времени активации в планетарной или кольцевой мельницах уменьшается интенсивность базального отражения на порошковых рентгеновских дифрактограммах при $4.0 \AA$ (рис. 1), за счёт незначительного уменьшения содержания адсорбированной мочевины. Сдвиг базального отражения (001) к меньшим углам (более высокие межплоскостные величины) в полученных композитах указывает на интеркаляцию мочевины в межслоевое пространство монтмориллонитовых пакетов с первых этапов активации. Первичный сдвиг базального отражения (001) указывает на присутствие воды и замещение сольватируемых катионов мочевиной в межслоевой структуре минерала. Отсутствие значительной потери веса на термогравиметрических кривых при диапазоне температур, характеризующих удаление сольватирующей воды из монтмориллонита, подтверждает эту интерпретацию. Отличительной чертой полученных результатов от результатов, поученных в предыдущих работах $[37,38]$ является полифункциональность синтезированных композитов из смесей при соотношении мочевины и монтмориллонита 1:1 за счет образования из избыточной мочевины отдельных покрытий на интеркалированной части глинистого минерала.

Интенсивность пика ИК-поглощения $\mathrm{NH}_{2}$ при $1155 \mathrm{~cm}^{-1}$ увеличивается по мере повышения времени активации, что связано с адсорбированным азотом на хлопьях (ультрамикроагрегаты) монтмориллонита (рис. 2). Растяжение $\mathrm{NH}_{2}$ на уровне $3468 \ldots 3500 \mathrm{~cm}^{-1}$ становится менее частым по мере увеличения времени синтеза в планетарной или кольцевой мельницах, что свидетельствует о более высокой степени «связывания» молекул азота. Незначительные сдвиги пиков $\mathrm{NH}_{2}$ и $\mathrm{NH}$ с увеличением времени работы планетарной мельницы соответствуют постепенному инкапсулированию в межслоевое пространство монтмориллонита.

В этом исследовании авторы были сфокусированы на разработке современных удобрений с «адресным» высвобождением нутриентов (CRF или SRF) с помощью оптимальных в экономическом отношении механохимических методов, таких как активация в планетарной или кольцевой мельницах. Первоначальный эксперимент по активации проводился со смесью глауконита и мочевины в соотношении $3: 1$ [38]. В этой работе использовался монтмориллонит как экономически доступный минерал в качестве ингибитора, отличительные соотношение глинистого минерала и мочевины и время активации. С одной стороны, при- готовление композитов в кольцевой мельнице является наиболее дешевым методом, с другой - синтез в планетарной мельнице проводится на порядок быстpeе и, следовательно, может существенно компенсировать трудозатраты в случае промышленной разработки.

До 23,2 \% азота интеркалируются в межслоевое пространство монтмориллонита. Около $20 \%$ азота адсорбируется на поверхности минеральных частиц, и около $5 \%$ абсорбируется в микропоровое пространство глинистых ультрамикроагрегатов. Минералогические, морфологические и структурные характеристики композитов позволяют заключить, что высвобождение азота из синтезированных удобрений будет происходить с разной скоростью. На начальной стадии после внесения удобрений будет расходоваться внешняя азотная микропленка или микропокрытие, после чего питательным веществом будет выступать интеркалированная и абсорбированная часть нутриента (N). Проведенные исследования показывают, что композиты, полученные путем механической активации смеси мочевины и монтмориллонита, подходят для испытаний в качестве экологически безопасных, многофункциональных и комплексных минеральных удобрений пролонгированного действия (SRF).

B итоге механохимическая активация смесей монтмориллонит-мочевина в соотношении 1:1 позволила выявить систематическое изменение внутренней структуры минералов, интеркаляцию азота с начала активации, формирование азотного покрытия по мере увеличения времени работы мельниц. Приготовленный композит при 11-минутном синтезе в планетарной мельнице (M1N1-pm11) представляют собой глинистый минерал с интеркалированным азотом в ядре и внешней микрокапсулой из азотной оболочки. Внешняя азотная оболочка лучше формируется по мере увеличения времени активации в планетарной мельнице относительно кольцевой. Активированные композиты обладают потенциалом для их использования как SRF с несколькими полезными функциями. Особенно это относится к композитам M1N1-pml1 и M1N1-rm120. Эти композиты с двумя типами азота изначально будут высвобождать питательные вещества с высокой скоростью за счёт внешней азотистой пленки. А впоследствии отдавать питательные вещества из интеркалированной структуры с пролонгированной или контролируемой скоростью.

\section{Выводы}

Основные выводы активации порошковых смесей на основе монтмориллонита и мочевины в соотношении 1:1 по различным операционным вариантам заключаются в следующем.

Доля интеркалированной мочевины в монтмориллоните (для смесей M1N1) незначительно изменяется в пределах 22,3...23,2 \% при активации в планетарной мельнице в течении 3,8 или 11 минут. Максимальная степень интеркаляции 23,2 \% была достигнута при активации в течении 3 минут. Однако, после 11 -минутной операции около $40 \ldots 50 \%$ агрегирован- 
ных частиц покрываются внешней оболочкой избыточной мочевины толщиной до 2,5 мкм.

Доля интеркалированной мочевины в монтмориллоните незначительно изменяется с 23,2 до 21,6 \% по мере увеличения времени активации с 30 до 120 минут в кольцевой мельнице. Доля адсорбированного азота на поверхности минеральных частиц составляет около $20 \%$, доля абсорбированного азота в микропоровое пространство - около $5 \%$. По мере увеличения времени активации образуются микрокристаллиты мочевины на поверхности минеральных частиц.

Минеральные продукты, полученные методом активации в планетарной или кольцевой мельницах, об-

\section{СПИСОК ЛИТЕРАТУРЫ/REFERENCES}

1. Tilman D., Cassman K.G., Matson P.A., Naylor R., Polasky S Agricultural sustainability and intensive production practices. Nature, 2002, vol. 418 (6898), pp. 671-677.

2. Matson P.A., Parton W.J., Power A.G., Swift M.J. Agricultural intensification and ecosystem properties. Science, 1997, vol. 277 (5325), pp. 504-509.

3. Vitousek P.M., Naylor R., Crews T., David M.B., Drinkwater L.E. Holland E., Johnes P.J., Katzenberger J., Martinelli L.A. Matson P.A. Nutrient imbalances in agricultural development. Science, 2009, vol. 324 (5934), pp. 1519-1520.

4. Pereira E.I., da Cruz C.C.T., Solomon A., Le A., Cavigelli M.A., Ribeiro C. Novel slow-release nanocomposite nitrogen fertilizers: the impact of polymers on nanocomposite properties and function. Industrial \& Engineering Chemistry Research, 2015, vol. 54 (14) pp. 3717-3725.

5. Ju X.-T., Xing G.-X., Chen X.-P., Zhang S.-L., Zhang L.-J., Liu X.-J., Cui Z.-L., Yin B., Christie P., Zhu Z.-L. Reducing environmental risk by improving $\mathrm{N}$ management in intensive Chinese agricultural systems. Proceedings of the National Academy of Sciences of the United States of America, 2009, vol. 106 (9), pp. 3041-3046.

6. Zhang Z.S., Chen J., Liu T.Q., Cao C.G., Li C.F. Effects of nitrogen fertilizer sources and tillage practices on greenhouse gas emissions in paddy fields of central China. Atmospheric Environment, 2016, vol. 144, pp. 274-281.

7. Akiyama H., Yan X., Yagi K. Evaluation of effectiveness of enhanced-efficiency fertilizers as mitigation options for N2O and NO emissions from agricultural soils: meta-analysis. Global Change Biology, 2010, vol. 16 (6), pp. 1837-1846.

8. Pereira E.I., Nogueira A.R., Cruz C.C.T., Guimarães G.G.F., Foschini M.M., Bernardi A.C.C., Ribeiro C. Controlled urea release employing nanocomposites increases the efficiency of nitrogen use by forage. ACS Sustainable Chemistry \& Engineering 2017, vol. 5 (11), pp. 9993-10001.

9. Xiao Y., Peng F., Zhang Y., Wang J., Zhuge Y., Zhang S., Gao H Effect of bag-controlled release fertilizer on nitrogen loss, greenhouse gas emissions, and nitrogen applied amount in peach production. Journal of Cleaner Production, 2019, vol. 234, pp. 258-274.

10. IPCC. Climate Change 2014: Mitigation of Climate Change: Working Group III Contribution to the Fifth Assessment Report of the Intergovernmental Panel on Climate Change, 2014. 1454 p.

11. Goulding K., Jarvis S., Whitmore A. Optimizing nutrien management for farm systems. Philosophical Transactions of the Royal Society B: Biological Sciences, 2008, vol. 363 (1491), pp. 667-680.

12. Al-Rawajfeh A.E., AlShamaileh E.M., Alrbaihat M.R. Clean and efficient synthesis using mechanochemistry: Preparation of kaolinite-KH2PO4 and kaolinite-(NH4)2HPO4 complexes as slow released fertilizer. Journal of Industrial and Engineering Chemistry, 2019, vol. 73, pp. 336-343.

13. Hermida L., Agustian J. Slow release urea fertilizer synthesized through recrystallization of urea incorporating natural bentonite using various binders. Environmental Technology \& Innovation, 2019, vol. 13, pp. 113-121. ладают потенциалом для их использования как удобрений пролонгированного действия (SRF) с несколькими полезными функциями. Композиты, синтезированные при 11-минутной или 120-минутной работе планетарной или кольцевой мельниц, соответственно, характеризуются двумя типами азота. Изначально удобрения будут высвобождать питательные вещества с высокой скоростью за счёт внешней пленки или покрытия из мочевины, после чего - питательные вещества из интеркалированной структуры с пролонгированным действием.

Работа выполнена при финансовой поддержке гранта Президента РФ № МК-213.2020.5.

14. Chen L., Chen X.L., Zhou C.H., Yang H.M., Ji S.F., Tong D.S., Zhong Z.K., Yu W.H., Chu M.Q. Environmental-friendly montmorillonite-biochar composites: Facile production and tunable adsorption-release of ammonium and phosphate. Journal of Cleaner Production, 2017, vol. 156, pp. 648-659.

15. Sha Z., Lv T., Staal M., Ma X., Wen Z., Li Q., Pasda G., Misselbrook T., Liu X. Effect of combining urea fertilizer with $P$ and $\mathrm{K}$ fertilizers on the efficacy of urease inhibitors under different storage conditions. Journal of Soils and Sediments, 2020, vol. 20 (4), pp. 2130-2140.

16. Boyandin A.N., Kazantseva E.A., Varygina D.E., Volova T.G. Constructing slow-release formulations of ammonium nitrate fertilizer based on degradable poly(3-hydroxybutyrate). Journal of Agricultural and Food Chemistry, 2017, vol. 65 (32), pp. 6745-6752.

17. Borges R., Baika L.M., Grassi M.T., Wypych F. Mechanochemical conversion of chrysotile/K2HPO4 mixtures into potential sustainable and environmentally friendly slow-release fertilizers. Journal of Environmental Management, 2018, vol. 206, pp. 962-970.

18. Chi Y., Zhang G., Xiang Y., Cai D., Wu Z. Fabrication of reusable temperature-controlled-released fertilizer using a palygorskitebased magnetic nanocomposite. Applied Clay Science, 2018, vol. 161, pp. 194-202.

19. Trenkel M.E. Controlled-Release and Stabilized Fertilizers in Agriculture. Paris, France, International Fertilizer Industry Association, 1997. $151 \mathrm{p}$.

20. Golbashy M., Sabahi H., Allahdadi I., Nazokdast H., Hosseini M. Synthesis of highly intercalated urea-clay nanocomposite via domestic montmorillonite as eco-friendly slow-release fertilizer. Archives of Agronomy and Soil Science, 2017, vol. 63 (1), pp. 84-95.

21. Teodorescu M., Lungu A., Stanescu P.O., Neamțu C. Preparation and properties of novel slow-release npk agrochemical formulations based on poly(acrylic acid) hydrogels and liquid fertilizers. Industrial \& Engineering Chemistry Research, 2009, vol. 48 (14), pp. 6527-6534.

22. Liang R., Liu M., Wu L. Controlled release NPK compound fertilizer with the function of water retention. Reactive and Functional Polymers, 2007, vol. 67 (9), pp. 769-779.

23. Liang R., Liu M. Preparation and properties of coated nitrogen fertilizer with slow release and water retention. Industrial \& Engineering Chemistry Research, 2006, vol. 45 (25), pp. 8610-8616.

24. Liu J., Yang Y., Gao B., Li Y.C., Xie J. Bio-based elastic polyurethane for controlled-release urea fertilizer: Fabrication, properties, swelling and nitrogen release characteristics. Journal of Cleaner Production, 2019, vol. 209, pp. 528-537.

25. Weian Z., Wei L., Yue'e F. Synthesis and properties of a novel hydrogel nanocomposites. Materials Letters, 2005, vol. 59 (23), pp. 2876-2880.

26. Sharma G.C. Controlled-release fertilizers and horticultural applications. Scientia Horticulturae, 1979, vol. 11 (2), pp. 107-129.

27. Wu J., Wei Y., Lin J., Lin S. Study on starch-graft-acrylamide/ mineral powder superabsorbent composite. Polymer, 2003, vol. 44 (21), pp. 6513-6520.

28. Ni B., Liu M., Lü S., Xie L., Wang Y. Environmentally friendly slow-release nitrogen fertilizer. Journal of Agricultural and Food Chemistry, 2011, vol. 59 (18), pp. 10169-10175. 
29. Cui Y., Xiang Y., Xu Y., Wei J., Zhang Z., Li L., Li J. Polyacrylic acid grafted natural rubber for multi-coated slow release compound fertilizer: Preparation, properties and slow-release characteristics. International Journal of Biological Macromolecules, 2020, vol. 146, pp. 540-548.

30. Borges R., Prevot V., Forano C., Wypych F. Design and kinetic study of sustainable potential slow-release fertilizer obtained by mechanochemical activation of clay minerals and potassium monohydrogen phosphate. Industrial \& Engineering Chemistry Research, 2017, vol. 56 (3), pp. 708-716.

31. Rashidzadeh A., Olad A. Slow-released NPK fertilizer encapsulated by NaAlg-g-poly(AA-co-AAm)/MMT superabsorbent nanocomposite. Carbohydrate Polymers, 2014, vol. 114, pp. 269-278.

32. Fatimah I., Yudha S.P., Rubiyanto D., Widodo I.D. Methenaminesmectite clay as slow release fertiliser: Physicochemical and kinetics study. Chemical Engineering Transactions, 2017, vol. 56 (2016), pp. 1639-1644

33. Wang Z., Chen J., Mao S., Han Y., Chen F., Zhang L., Li Y., Li C. Comparison of greenhouse gas emissions of chemical fertilizer types in China's crop production. Journal of Cleaner Production, 2017, vol. 141, pp. 1267-1274

34. Borges R., Brunatto S.F., Leitão A.A., De Carvalho G.S.G., Wypych F. Solid-state mechanochemical activation of clay minerals and soluble phosphate mixtures to obtain slow-release fertilizers. Clay Minerals, 2015, vol. 50 (02), pp. 153-162.

35. Lei Z., Cagnetta G., Li X., Qu J., Li Z., Zhang Q., Huang J. Enhanced adsorption of potassium nitrate with potassium cation on $\mathrm{H}_{3} \mathrm{PO}_{4}$ modified kaolinite and nitrate anion into Mg-Al layered double hydroxide. Applied Clay Science, 2018, vol. 154, pp. 10-16.

36. Hussien R.A., Donia A.M., Atia A.A., El-Sedfy O.F., El-Hamid A.R.A Rashad R.T. Studying some hydro-physical properties of two soils amended with kaolinite-modified cross-linked poly-acrylamides. CATENA, 2012, vol. 92, pp. 172-178.

37. Rudmin M., Banerjee S., Yakich T., Tabakaev R., Ibraeva K., Buyakov A., Soktoev B., Ruban A. Formulation of a slow-release fertilizer by mechanical activation of smectite/glauconite and urea mixtures. Applied Clay Science, 2020, vol. 196, pp. 105775.

38. Rudmin M., Abdullayev E., Ruban A., Buyakov A., Soktoev B. Mechanochemical preparation of slow release fertilizer based on glauconite-urea complexes. Minerals, 2019, vol. 9 (507), pp. 1-10.
39. Rudmin M., Mazurov A., Banerjee S. Origin of ooidal ironstones in relation to warming events: Cretaceous-Eocene Bakchar deposit, south-east Western Siberia. Marine and Petroleum Geology, 2019, vol. 100, pp. 309-325.

40. Rudmin M., Banerjee S., Makarov B., Mazurov A., Ruban A., Oskina Y., Tolkachev O., Buyakov A., Shaldybin M. An investigation of plant growth by the addition of glauconitic fertilizer. Applied Clay Science, 2019, vol. 180, pp. 1-8.

41. Rudmin M., Reva I., Gunko A., Mazurov A., Abramova R. Structural-chemical features and morphology of glauconites in sedimentary iron ore of Bakchar prospect (Western Siberia). IOP Conference Series: Earth and Environmental Science, 2015, vol. 27 (012026), pp. 1-6.

42. Rudmin M., Banerjee S., Mazurov A., Makarov B., Martemyanov D. Economic potential of glauconitic rocks in Bakchar deposit (S-E Western Siberia) for alternate potash fertilizer. Applied Clay Science, 2017, vol. 150, pp. 225-233.

43. Rudmin M., Banerjee S., Makarov B. Evaluation of the effects of the application of glauconitic fertilizer on oat development: a twoyear field-based investigation. Agronomy, 2020, vol. 10 (872), pp. 1-12.

44. Schaber P.M., Colson J., Higgins S., Thielen D., Anspach B., Brauer J. Thermal decomposition (pyrolysis) of urea in an open reaction vessel. Thermochimica Acta, 2004, vol. 424 (1-2), pp. $131-142$.

45. Kristóf J., Frost R.L., Horváth E., Kocsis L., Inczédy J. Thermoanalytical investigations on intercalated kaolinites. Journal of Thermal Analysis and Calorimetry, 1998, vol. 53 (2), pp. 467-475.

46. Makó É., Kristóf J., Horváth E., Vágvölgyi V. Kaolinite-urea complexes obtained by mechanochemical and aqueous suspension techniques - a comparative study. Journal of Colloid and Interface Science, 2009, vol. 330 (2), pp. 367-373.

47. Emmerich K., Madsen F.T., Kahr G. Dehydroxylation behavior of heat-treated and steam-treated homoionic cis-vacant montmorillonites. Clays and Clay Minerals, 1999, vol. 47 (5), pp. 591-604.

Поступила 29.09.2020 2. Received: 29 September 2020.

\section{Информация об авторах}

Рудмин М.A., кандидат геолого-минералогических наук, доцент отделения геологии Инженерной школы природных ресурсов Национального исследовательского Томского политехнического университета.

Pева И.В., аспирант Инженерной школы природных ресурсов Национального исследовательского Томского политехнического университета.

Якич T.Ю., кандидат геолого-минералогических наук, доцент отделения геологии Инженерной школы природных ресурсов Национального исследовательского Томского политехнического университета.

Соктоев Б.P., кандидат геолого-минералогических наук, доцент отделения геологии Инженерной школы Национального исследовательского Томского политехнического университета.

Буяков $\boldsymbol{A . C}$., ассистент Инженерной школы новых производственных технологий Национального исследовательского Томского политехнического университета; младший научный сотрудник Института физики прочности и материаловедения Сибирского отделения Российской академии наук.

Tабакаев P.Б., кандидат технических наук, научный сотрудник научно-образовательного центра И.Н. Бутакова Инженерной школы энергетики Национального исследовательского Томского политехнического университета.

Ибраева К., аспирант научно-образовательного центра И.Н. Бутакова Инженерной школы энергетики Национального исследовательского Томского политехнического университета. 
UDC 549.02:54.052:553.611.6

\title{
MONTMORILLONITE AS A PROSPECTIVE COMPOSITE MINERAL FOR THE CREATION OF MODERN SLOW-RELEASE FERTILIZERS
}

\author{
Maxim A. Rudmin'1, \\ rudminma@tpu.ru \\ Igor V. Reva', \\ igor_1993@mail.ru \\ Tamara Yu. Yakich1, \\ cherkasovatu@tpu.ru
}

\author{
Ales S. Buyakov ${ }^{1,2}$, \\ alesbuyakov@gmail.com
}

Roman B. Tabakaev', tabakaevRB@tpu.ru

Kanipa Ibraeva ${ }^{1}$, kti1@tpu.ru

\author{
Bulat R. Soktoev', \\ bulatsoktoev@tpu.ru \\ 1 National Research Tomsk Polytechnic University, \\ 30, Lenin avenue, Tomsk, 634050, Russia. \\ 2 Institute of Strength Physics and Materials Science of Siberian Branch Russian Academy of Sciences, \\ 2/4, Akademicheskii avenue, Tomsk, 634055, Russia.
}

The relevance of the research. The solution of environmental problems in the agricultural sector is possible through the use of new slowreleased or controlled release fertilizers. This article presents options for using montmorillonite as a component of modern nitrogen fertilizers with controlled properties and the results of studying mineral transformations in the mechanochemical activation at various parameters.

The main aim of the work was to evaluate activation mechanisms of the montmorillonite as an inhibitor of nitrogen composites for creating slow-release fertilizers.

The methods: mechanochemical activation by planetary and ring mills, X-ray diffraction, scanning electron microscopy, infrared spectroscopy, differential thermal analysis.

Results. The proportion of intercalated urea in montmorillonite (for M1N1 mixtures) is slightly changed within 22,3...23,2 \% for the planetary mill activation for 3,8 or 11 minutes. The maximum intercalation degree of $23,2 \%$ was achieved in the activation for 3 minutes. However, about $40 . .50 \%$ of the aggregated particles are covered with an outer shell of excess urea up to $2,5 \mu \mathrm{m}$ in the thick after an 11minute operation for the planetary mill. The proportion of intercalated urea in montmorillonite is slightly changed from 23,2 to $21,6 \%$ for the activation time increases from 30 to 120 minutes in a ring mill. While the activation time was increased, urea microcrystallites were formed on the surface of mineral particles. Mineral products synthesized by planetary or ring mill activation have the potential to be used as slowrelease fertilizers with several beneficial functions. Composites synthesized with 11-minute or 120-minute planetary or ring mills, respectively, are characterized by two types of nitrogen. Fertilizers will initially release nutrients at a high rate from the outer urea film. After that, exchangeable nitrogen will be released from the interlayer space of montmorillonite, thereby providing prolonged nutrition of the plants.

\section{Key words:}

Montmorillonite, clay minerals, mineral fertilizers, mechanochemical activation, nitrogen fertilizers.

This study was supported by the grant from the President of the Russian Federation to support young Russian scientists, project number MK-213.2020.5.

\section{Information about the authors}

Maxim A. Rudmin, Cand. Sc., associate professor, National Research Tomsk Polytechnic University.

Igor V. Reva, postgraduate, National Research Tomsk Polytechnic University.

Tamara Yu. Yakich, Cand. Sc., associate professor, National Research Tomsk Polytechnic University.

Bulat R. Soktoev, Cand. Sc., associate professor, National Research Tomsk Polytechnic University.

Ales S. Buyakov, assistant professor, National Research Tomsk Polytechnic University; junior researcher Institute of Strength Physics and Materials Science of Siberian Branch Russian Academy of Sciences.

Roman B. Tabakaev, Cand. Sc., researcher, National Research Tomsk Polytechnic University.

Kanipa Ibraeva, postgraduate student, National Research Tomsk Polytechnic University. 